\title{
Improving Power System Dynamic Behavior Through Doubly Fed Induction Machines Controlled by Static Converter Using Fuzzy Control
}

\author{
Rogério G. de Almeida, J. A. Peças Lopes, Senior Member, IEEE, and J. A. L. Barreiros
}

\begin{abstract}
This work presents a control strategy applied to a doubly fed induction machine (DFIM) for wind generation in a medium power system. In order to control the active power and reactive power exchange between the machine and the grid, the rotor is fed by a link of AC-DC-AC converters modeled as voltage and controlled current sources, respectively. The control of the rotor-side converter is realized by fuzzy controllers whose performances are compared with that of conventional Proportional-Integral controllers. The control of the grid-side converter is carried out by a control block based on the instantaneous power theory and it is controlled to maintain the DC link voltage constant and to improve the power factor of the system. Some design considerations of the control schemes are discussed. A multimachine model is used in digital simulations to assess the dynamic behavior of the power system control scheme proposed in this work.
\end{abstract}

Index Terms-Control systems, converters, induction machines, power system dynamic stability, turbines.

\section{INTRODUCTION}

$\mathbf{T}$ HE INCREASING integration of doubly fed induction machines (DFIM) controlled by static converters for wind generation into power grids is currently a generalized tendency in numerous countries, namely in European grids. This fact is directly related with the control flexibility offered by static converters that make possible to maintain terminal voltage constant when induction generator operates with variable speed as well as to allow independent active and reactive power control exchanged between the machine and the grid with better use of the available wind energy.

In order to understand the impact of the presence of DFIM in the dynamic behavior of the power system (i.e., phenomena in the frequency range of 0.1 to $10 \mathrm{~Hz}$ ), reduced order models have been used, ignoring the dc component and the fast transients of the stator currents and avoiding the inclusion of fast transients and higher order harmonics related with high switching frequencies of the electronic interfaces, as explained in [1]-[5]. These models reproduce the electromechanical behavior and the

Manuscript received January 23, 2004. This work was supported by Fundação para a Ciência e Tecnologia de Portugal (FCT), in the framework of the DIPTUNE POCTI/41614/ESE/2001 project. Paper no. TPWRS-00573-2003.

R. G. de Almeida is with INESC Porto, 4200-465 Porto, Portugal (e-mail: ralmeida@inescporto.pt).

J. A. P. Lopes is with Instituto de Engenharia de Sistemas e Computadores do Porto (INESC Porto) and Faculdade de Engenharia da Universidade do Porto (FEUP), 4200-465 Porto, Portugal (e-mail: jpl@fe.up.pt).

J. A. L. Barreiros is with INESC Porto, 4200-465 Porto, Portugal, on leave from the Universidade Federal do Pará, Pará, Brazil (e-mail: barreiro@ufpa.br). Digital Object Identifier 10.1109/TPWRS.2004.836271 control strategy of the energy converters during system disturbances, like it is done for HVDC converters modeling in power system dynamic analysis [6], provided that the electronic interfaces operate within the designed limits.

Due to their simple structure and robust performance, proportional-integral (PI) controllers are the most common controllers used to generate the signal to turn on and turn off the converter switches that control the DFIM. However, the success of the PI controller, and consequently, the performance of the machine depend on an appropriate choice of the PI gains. Tuning the PI gains to optimize performance is not a trivial task, still more when the process is nonlinear and may vary during operation.

To adjust the PI gains correctly it requires the knowledge of the dynamic modeling and behavior of the doubly fed induction machine. The dynamic and steady state equations that describe the behavior of the DFIM are quite described in literature. These models are based on a single-cage representation (reduced order model) [1]-[3] or a double-cage model which represents the transient and sub-transient behavior of the machine more accurately [4], [5]. In both mathematical models, it is verified the presence of nonlinear and coupling terms that turns difficult the design of the PI-controller.

In [3], the nonlinear and coupling terms are assumed as disturbances and an observer-state controller is designed. This control scheme is interesting for small disturbances where the modeling of the DFIM can be linearized. However, for a severe disturbance on the system, such as a solid three-phase short circuit, the linearization does not predict the behavior of the machine correctly.

The nonlinear and coupling terms presents in machine dynamic equation must be considered because they affect the controller's performance. In [5], the importance of the correct design of the control system is discussed where, through an adequate adjustment of the PI gains based on the rotor dynamic behavior, it is possible to limit the generator currents during a fault and, consequently, the crowbar (breaker circuit designed to protect the converters) does not operate and the converters may be maintained in operation. This fact plays an important role to improve the power system dynamic behavior, since it contributes to provide to these converters a ride through default capability. Up until now, wind energy conversion systems have been designed to be disconnected fast from the grid if a large voltage dip occurs. This may happen as a result of a large network disturbance, such as a short circuit, and it may trigger a sequence of other events leading to dynamic behavior problems in the network. 
Therefore to obtain an optimal integration of wind energy in the system, the large wind farms must be able to withstand network disturbances that are successfully eliminated i.e., be able to participate in the control and stabilization of the power system following system disturbances. A robust control in the DFIM may represent an excellent possibility to improve network dynamic behavior, as mentioned in [7]-[9].

When using PI controllers, the nonlinear model of the machine implicates in tuning the gains carefully for different operation conditions. The adjustment of the PI gains to control the DFIM may become more difficult when the dimension of the power system increases significantly, or in the case where the machine operates in an isolated system, due to the stronger coupling of active and reactive powers.

Fuzzy control provides a systematic way to control a nonlinear process based on human experience. This may be considered as a heuristic approach that can improve the performance of closed loop systems. A properly designed fuzzy controller can give higher performance in presence of variations in parameters, load and external disturbances, than traditional PI controllers [10], [11]. The fuzzy controller's performance is based on its ability to simultaneously process several rule implications providing a more complete output. Due to the fuzzy control robustness concerning many nonlinear processes, this work proposes the design of two fuzzy controllers to control the rotor speed and the terminal voltage of the DFIM whose output signals are used to control the rotor-side converter.

In this paper, the performance of the DFIM controlled by fuzzy control is compared with one controlled by conventional well-adjusted PI controllers for distinct disturbances applied in a small test system with Diesel unit and a connection to an infinite bus bar. The rotor-side and grid-side converters are modeled as voltage source and current source, respectively, and a crowbar circuit is used to protect them when rotor currents exceed a certain limit. The DFIM model with the designed control approach was embedded in full dynamic simulation tool in order to evaluate the general impacts in system dynamic behavior that result from this control scheme.

In order to evaluate the performance of the scheme proposed to control the rotor-side converter, operational aspects concerning to the grid-side converter control will not be depicted in detail because it is not the main objective of this work. However, the grid-side converter is controlled to maintain the dc link voltage constant through control blocks based on instantaneous power theory [12] assuming it operates with unit power factor.

\section{Mathematical Model of the DFIM}

In this work, the single cage representation (reduced order model) of the doubly fed induction machine was adopted. Although doubly cage mode provides better accuracy transient network model, similar results are obtained with a single cage representation in stability studies as discussed in [4], [5].

In generator operation the rotor and stator currents are considered outputs instead of inputs. Both the active power and reactive power have a positive sign when they are fed into the grid.
Using the generator convention, the following set of equations for single cage model results in [5]

$$
\begin{aligned}
& \left\{\begin{array}{l}
v_{d s}=-R_{s} i_{d s}-\omega_{s} \lambda_{q s}+\frac{d \lambda_{d s}}{d t} \\
v_{q s}=-R_{s} i_{q s}+\omega_{s} \lambda_{d s}+\frac{d \lambda_{q s}}{d t}
\end{array}\right. \\
& \left\{\begin{array}{l}
v_{d r}=R_{r} i_{d r}-\left(\omega_{s}-\omega_{r}\right) \lambda_{q r}+\frac{d \lambda_{d r}}{d t} \\
v_{q r}=R_{r} i_{q r}+\left(\omega_{s}-\omega_{r}\right) \lambda_{d r}+\frac{d \lambda_{q r}}{d t} .
\end{array}\right.
\end{aligned}
$$

Here, $v$ is the voltage $(\mathrm{V}), R_{s}$ and $R_{r}$ are, respectively, the stator and rotor resistances $(\Omega), i$ is the current (A), $\omega_{s}$ is the stator electrical frequency $(\mathrm{rad} / \mathrm{s}), \omega_{r}$ is the rotor electrical frequency $(\mathrm{rad} / \mathrm{s})$, and $\lambda$ is the flux linkage (Wb) (the time is in seconds).

In (1) and (2), subscripts $d$ and $q$ denote the direct and quadrature axes of the reference frame. Also, in these equations, subscripts $s$ and $r$ denote stator and rotor variables. The $d-q$ reference frame is rotating at synchronous speed with the $q$-axis $90^{\circ}$ ahead of the $d$-axis.

The flux leakage in (1) and (2) is defined as

$$
\begin{aligned}
& \left\{\begin{array}{l}
\lambda_{d s}=-L_{s s} i_{d s}+L_{m} i_{d r} \\
\lambda_{q s}=-L_{s s} i_{q s}+L_{m} i_{q r}
\end{array}\right. \\
& \left\{\begin{array}{l}
\lambda_{d r}=L_{r r} i_{d r}-L_{m} i_{d s} \\
\lambda_{q r}=L_{r r} i_{q r}-L_{m} i_{q s} .
\end{array}\right.
\end{aligned}
$$

$L_{s s}$ represents the self-inductance of the stator windings, $L_{r r}$ the self-inductance of the rotor windings, and $L_{m}$ the mutual (magnetizing) inductance between the stator and the rotor windings.

For the representation of the induction machine in power system stability studies, it is a practice to represent the machine by a simple voltage behind a transient reactance equivalent circuit where the stator transients are neglected. From (1)-(4), it is possible to get the relationship between stator current and voltage in terms of a voltage behind the transient reactance

$$
\begin{aligned}
& \left\{\begin{array}{l}
v_{d s}=-R_{s} i_{d s}+X^{\prime} \lambda_{q s}+e_{d} \\
v_{q s}=-R_{s} i_{q s}-X^{\prime} \lambda_{d s}+e_{q}
\end{array}\right. \\
& \left\{\begin{array}{l}
\frac{d e_{d}}{d t}=-\frac{1}{T_{o}}\left[e_{d}-\left(X-X^{\prime}\right) i_{q s}\right]+s \omega_{s} e_{q}-\omega_{s} \frac{L_{m}}{L_{r r}} v_{q r} \\
\frac{d e_{q}}{d t}=-\frac{1}{T_{o}}\left[e_{q}+\left(X-X^{\prime}\right) i_{d s}\right]-s \omega_{s} e_{d}+\omega_{s} \frac{L_{m}}{L_{r r}} v_{d r} .
\end{array}\right.
\end{aligned}
$$

Here, $X$ is the open circuit reactance, given by $\omega_{s}$ Lss, $X^{\prime}$ is the transient reactance or blocked rotor reactance, given by $\omega_{s}\left(\mathrm{~L}_{s s}-\mathrm{L}_{m}^{2} / \mathrm{L}_{r r}\right), e_{d}$ and $e_{q}$ are the voltages behind transient reactance of direct and quadrature axis, respectively and $T_{o}$ is the rotor open circuit time constant (s), given by $\mathrm{L}_{r r} / \mathrm{Rr}$.

To complete the asynchronous machine state model, it is necessary to combine the equations that describe the electrical voltage and current components of the machine with a swing equation that provides the rotor speed state variable. For simplicity, the differential rotor swing equation, which models the dynamic behavior of the machine, can be described by

$$
\frac{d \omega_{r}}{d t}=\frac{1}{J}\left(T_{m}-T_{e}\right)
$$

where $T_{m}$ is the mechanical torque, $T_{e}$ is the electromechanical torque and $J$ is the moment of the machine inertia $\left(\mathrm{kg} \cdot \mathrm{m}^{2}\right)$. 
The electromagnetic torque variable for these equations is calculated using

$$
T_{e}=e_{d} i_{d s}+e_{q} i_{q s} .
$$

The use of a single-mass equivalent for the mechanical systems leads to a more damped behavior than when a multiple mass model is used [13]. Such an assumption, however, does not compromise the quality of the comparative analysis performed in this work.

\section{StRUCTURE OF THE Wind CONVERSION SySteM}

\section{A. Wind Turbine}

The mechanical power $(\mathrm{W})$ in the wind turbine shaft is given by the following equation:

$$
P_{m}=\frac{1}{2} \rho C_{p} A U_{w}^{3} .
$$

$C_{p}$ is the power coefficient of the wind turbine, $A\left(\mathrm{~m}^{2}\right)$ is the effective area covered by the turbine, $U_{W}(\mathrm{~m} / \mathrm{s})$ is the wind speed and $\rho\left(\mathrm{Kg} / \mathrm{m}^{3}\right)$ is the air density.

The calculation of the power coefficient requires knowledge of aerodynamics and some computations. However, numerical approximations have been developed. In this work, the following function suggested in [12] is used:

$$
\begin{aligned}
C_{p}(\lambda, \theta) & =0.22\left(\frac{116}{\lambda_{i}}-0.4 \theta-5\right) e^{-12.5 / \lambda_{i}} \\
\frac{1}{\lambda_{i}} & =\frac{1}{\lambda+0.08 \theta}-\frac{0.035}{\theta^{3}+1} .
\end{aligned}
$$

The tip speed ratio is defined as

$$
\lambda=\frac{\omega_{t} R}{U_{w}}
$$

where $R(\mathrm{~m})$ is the blade radius and $\omega_{t}$ is the wind turbine rotor speed (rad_elec/s).

This equations leads to the $C_{p}(\lambda, \theta)$ versus $\lambda$ characteristic curves for various values of the $\theta$ (pitch angle of the blades, in degrees). So, the initial wind turbine rotor speed $\left(\omega_{t}\right)$ when the turbine operates with a fixed mechanical power can be obtained.

\section{B. Model of the DFIM Converters}

Since the simulation of the fundamental power system dynamic behavior does not requires a detailed modeling of power electronics, the converters are modeled as voltage source and/or current source. From the DFIM model defined in the previous section, the rotor-side converter is assumed as a voltage source injected to rotor $(\mathrm{C} 1)$ and the grid-side converter is assumed as a controlled current source (C2). A general schematic of the DFIM, static converters and controllers is depicted in Fig. 1.

Converter $\mathrm{C} 1$ controls the injected rotor voltage that allows the control of the electromagnetic torque, which must follow the reference speed provided by the control system. It can also provide reactive power control and voltage control or unit power factor of the machine.

Converter $\mathrm{C} 2$ represents a shunt power converter. As converter $\mathrm{C} 1$ can provide reactive power control, converter $\mathrm{C} 2$ may offer additional voltage support capabilities in conditions of excessive speed ranges or in transient operations. In this work, as

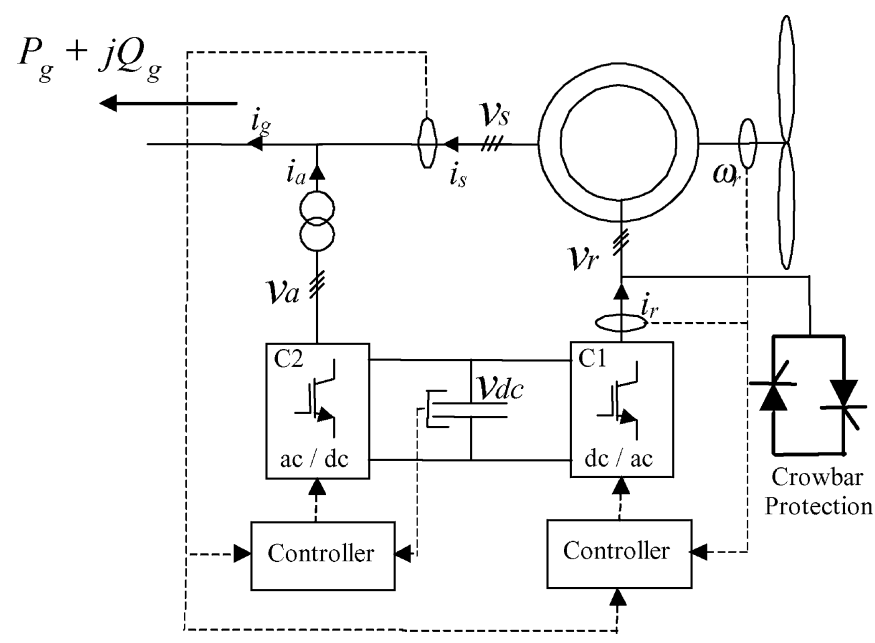

Fig. 1. General schematic of the DFIM, converters and controllers.

cited previously, only the control of $\mathrm{C} 1$ is discussed in the next section.

For this model, it was assumed that the dc link voltage between the converters is kept constant by converter $\mathrm{C}_{2}$, as described in [8].

\section{SYNTHESIS OF THE ROTOR-SIDE CONVERTER}

This section deals with the synthesis of two schemes of control, PI-controllers and fuzzy controllers, for the control of the rotor-side converter. Both schemes are designed to achieve the following control objectives.

- Perform rotor speed and terminal voltage reference tracking.

- Parametric robustness, allowing good insensibility against ageing, over-heating, etc.

A large variety of distinct control schemes for variable speed wind turbines has been used, mainly based on PI controllers [3]-[5]. Due to the rotor-side converter being modeled as voltage source, the concept consisting of $d-q$ voltage regulators for the generator control is considered for both PI and fuzzy controllers.

\section{A. PI-Controllers Design}

To achieve the rotor speed and voltage terminal control, the rotor-side converter operates in a stator-flux $d-q$ reference frame allowing a decoupled control. More details of this scheme are depicted in [1] and [3].

In this work, besides the PI controllers of the rotor speed and terminal voltage, additional PI blocks were included (forming an internal current control loop) to improve the problems due to cross-coupling and inherent nonlinearities, as suggested in [3].

Fig. 2 shows the control loops with the PI controllers (with $K_{v}, K_{t}, T_{v}$ and $T_{t}$ given in terms of machine parameters [3]). In this figure, $K_{p} \mathrm{~s}$ and $K_{I} \mathrm{~s}$ are the proportional and integral gains, respectively.

Although the degree of complexity is larger due to the increased number of parameters, the tracking trajectory, disturbance rejection and parametric robustness may be improved using this cascade structure, which was also used in [4] and [8]. 

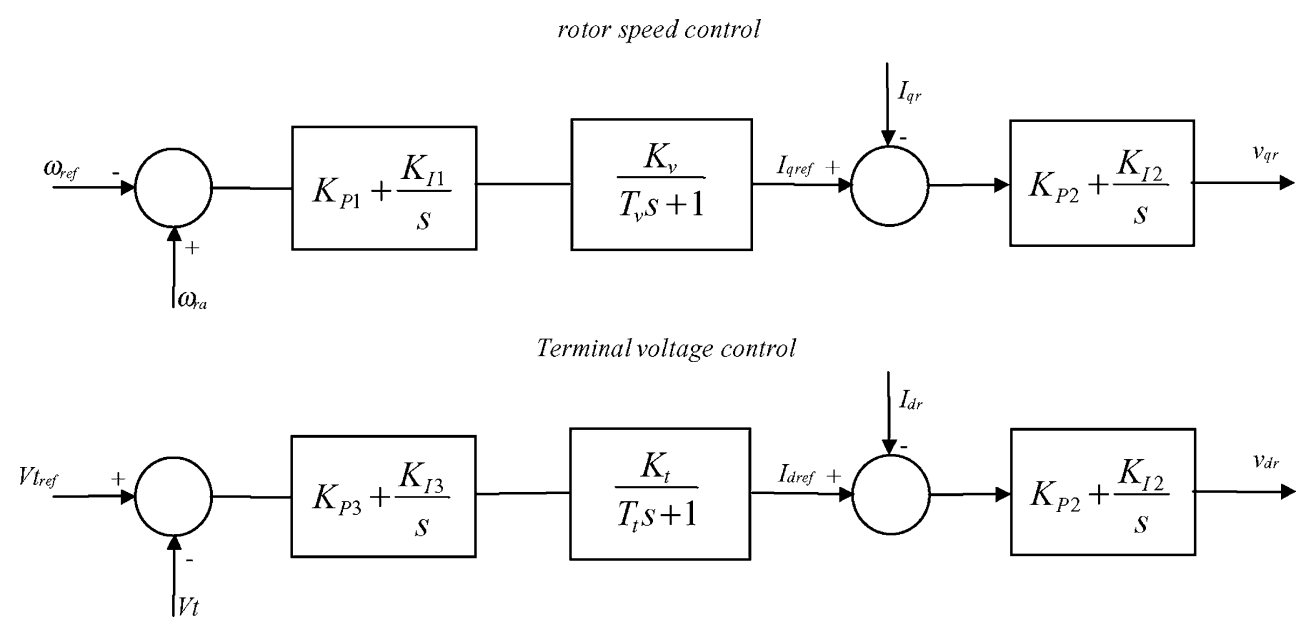

Fig. 2. Block diagram for speed and terminal voltage control.

Classical techniques of design, based on some aspects of the output curves for special inputs applied on the system, were used to obtain initial values for the PI gains of the controllers [15]. Then, the gains were carefully adjusted for trying and error through several simulations (using the power system and the faults presented in the next section), in order to obtain minimum variations for the controlled variables involved in the design. After this long process of tuning, the values obtained for the PI gains are presented in Table I, jointly with the machine parameters cited above.

\section{B. Fuzzy Controllers Design}

Only two fuzzy controllers were used. The structures of both consist of a fuzzyfication block, a fuzzy inference engine (with a knowledge base containing the rules and the membership functions), and a defuzzification block [10]. Figs. 3 and 4 show the blocks diagrams of the fuzzy control FLC-01 (for rotor speed control) and the fuzzy control FLC-02 (for terminal voltage control), respectively. All the inputs and the outputs are normalized for the base values defined to the system and depicted in the Appendix.

The number and form of the memberships functions defining the fuzzy values of both controllers (for the inputs and outputs) were defined off-line, and the universes of discourse for each variable were normalized to distinct values according with the behavior of the variables observed during simulations.

Standard triangular membership functions were used for both the input and the output fuzzy sets of the fuzzy controllers. The designed fuzzy sets for rotor speed control are shown in Fig. 5 and for terminal voltage control are shown in Fig. 6, respectively.

The control rules of the fuzzy controllers FLC-01 and FCL-02 are represented by a set of heuristically chosen fuzzy rules (that are frequently suggested by experts in the problem on consideration). The designed fuzzy rules used in this work for both controllers are given in Tables II and III, respectively.

The fuzzy sets have been defined as: NL, negative large, $\mathrm{N}$, negative, $\mathrm{P}$, positive, PL, positive large, and $\mathrm{ZE}$, zero, respectively.
TABLE I

GAINS AND TIME CONSTANTS DEFINED FOR PI CONTROLLERS

\begin{tabular}{c|c}
\hline Gains & Values \\
\hline$K_{p 1}$ & 20.27 \\
\hline$K_{11}$ & 15.76 \\
\hline$K_{p 2}$ & 0.04434 \\
\hline$K_{12}$ & 0.00321 \\
\hline$K_{p 3}$ & 15.06 \\
\hline$K_{/ 3}$ & 10.50 \\
\hline$K_{v}$ & 0.0321 \\
\hline$K_{t}$ & 0.0321 \\
\hline Time constant & Values \\
\hline$T_{v}$ & 0.4434 \\
\hline$T_{t}$ & 0.4434 \\
\hline
\end{tabular}

\section{Simulation Results}

In order to evaluate the impact of the fuzzy control based on the approach used in the DFIM on the dynamic behavior of a power system, comparative tests regarding to the PI control have been performed through dynamic simulation, for some disturbances in a test system. The power system used in this work for the simulation tests is presented in Fig. 7 [16]. The general multimachine power system model developed in [17] is used to define, in a compact form, the transmission network and the machines stator equations. The full power system dynamic model involves the mathematical description of the electrical and mechanical behavior of the synchronous generator connected to bus 3 , represented through a fourth-order transient model [18], [19] and including also the automatic voltage regulator (IEEE type 1), an isochronous speed governor and a simple first order model for the equivalent of two Diesel motors, as described in [17]. A dedicated dynamic power system simulation software package, using MATLAB ${ }^{\mathrm{TM}}$, was developed for this purpose.

In this work, 12 machines, which operate identically, constitute a wind park and an equivalent machine represents all of them. The conventional synchronous machine and the Wind system parameters are shown in the Appendix.

The simulated disturbances consist of: a) load loss at bus 5 and b) a symmetrical impedance three-phase short circuit at bus 


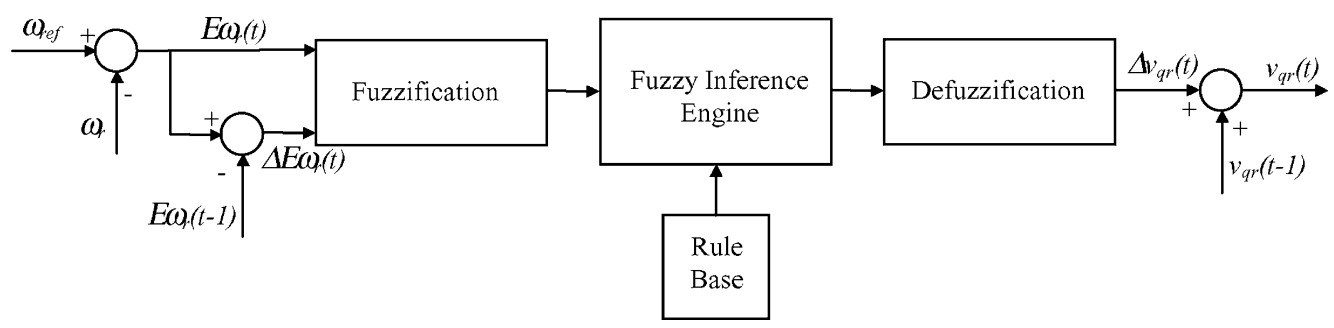

Fig. 3. Block diagram of the fuzzy controller FLC-01.

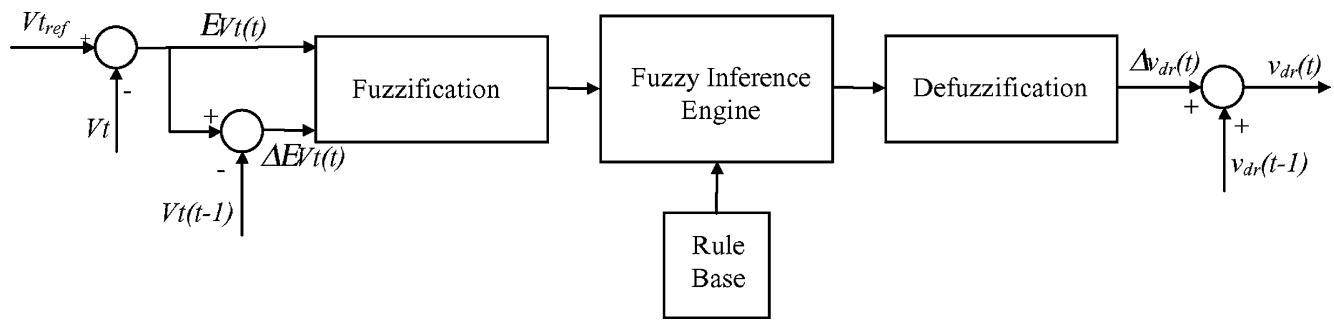

Fig. 4. Block diagram of the fuzzy controller FLC-02.
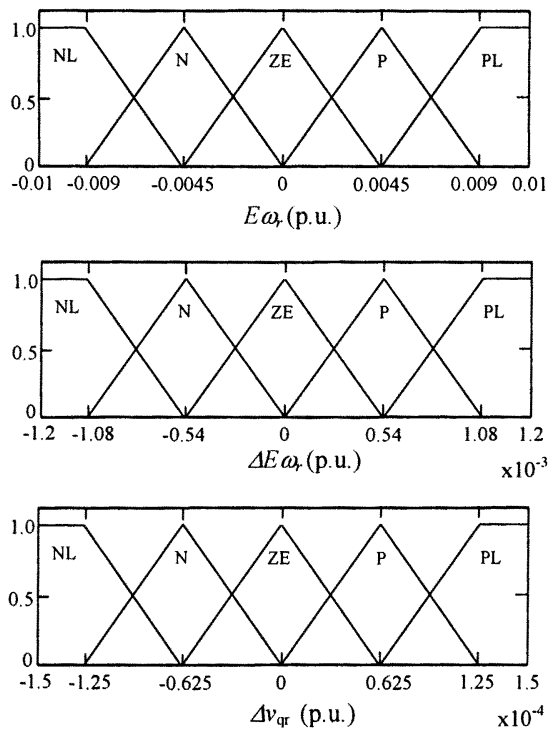

Fig. 5. Triangular memberships functions for inputs and output fuzzy sets of the fuzzy controllers FCL-01.

6 (defined through the connection of small impedance between this node and earth).

The operating conditions of the DFIM were defined such that it is set to operate with rotor speed equal to 1.01 p.u. and terminal voltage equal to 1.02 p.u. It is assumed a constant wind speed of $15 \mathrm{~m} / \mathrm{s}$ during all the simulation period.

\section{A. Load Loss at Bus-Bar 5}

Load loss was simulated here through a sudden disconnection of the load at bus 5 (see Fig. 7).

Results: At $\mathrm{t}=1 \mathrm{~s}$ the load at bus 5 was disconnected. Fig. 8 shows the behavior of the rotor speed in the DFIM with fuzzy and PI control schemes, respectively. The fuzzy control efficiency allows the rotor speed of the DFIM to reach the steady state in $5 \mathrm{~s}$, approximately, with lower overshoot. Similar behavior is seen in Fig. 9 for the terminal voltages. It is important
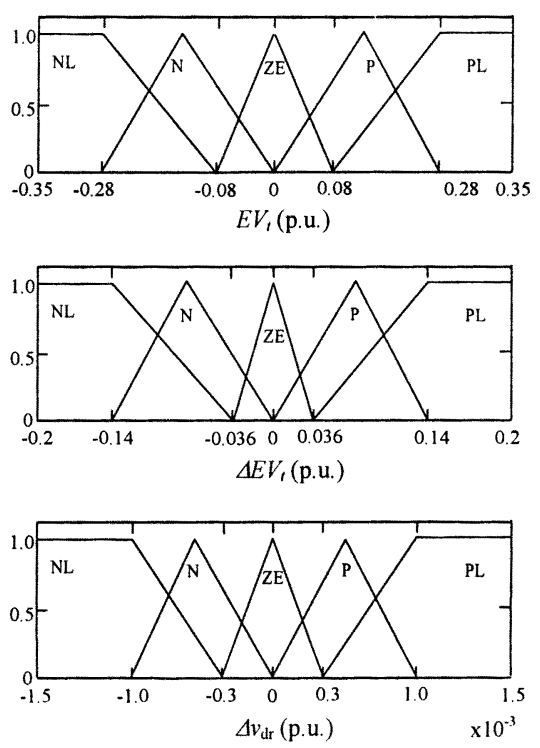

Fig. 6. Triangular memberships functions for inputs and output fuzzy sets of the fuzzy controllers FCL-02.

TABLE II

RULE BASE FOR FLC-01

\begin{tabular}{l|c|c|c|c|c|c}
\hline \multicolumn{2}{c|}{} & \multicolumn{5}{|c}{$\Delta E \omega_{r}$} \\
\cline { 3 - 7 } \multicolumn{2}{c|}{} & NL & $\mathbf{N}$ & $\mathbf{Z E}$ & $\mathbf{P}$ & PL \\
\hline \multirow{4}{*}{$E \omega_{r}$} & $\mathbf{N L}$ & PL & PL & PL & P & ZE \\
\cline { 2 - 7 } & $\mathbf{N}$ & PL & PL & P & ZE & N \\
\cline { 2 - 7 } & $\mathbf{Z E}$ & P & P & ZE & N & N \\
\cline { 2 - 7 } & $\mathbf{P}$ & P & ZE & N & NL & NL \\
\cline { 2 - 7 } & PL & ZE & N & NL & NL & NL \\
\hline
\end{tabular}

to observe that the fuzzy control scheme does not utilize information of the rotor current to control the DFIM as in the PI controllers and even so a better control performance is verified.

After the load loss, the terminal voltage tends to increase but in both PI and fuzzy schemes the voltage $v_{d r}$ is increased to maintain the terminal voltage constant. This fact increases the 
TABLE III

RULE BASE FOR FCL-02

\begin{tabular}{l|c|c|c|c|c|c}
\hline \multicolumn{2}{c|}{} & \multicolumn{6}{|c}{$\Delta E V_{t}$} \\
\cline { 3 - 8 } \multicolumn{2}{c|}{} & $\mathbf{N L}$ & $\mathbf{N}$ & $\mathbf{Z E}$ & $\mathbf{P}$ & $\mathbf{P L}$ \\
\hline \multirow{4}{*}{$E V_{t}$} & $\mathbf{N L}$ & $\mathrm{NL}$ & $\mathrm{NL}$ & $\mathrm{NL}$ & $\mathrm{N}$ & $\mathrm{ZE}$ \\
\cline { 2 - 7 } & $\mathbf{N}$ & $\mathrm{NL}$ & $\mathrm{NL}$ & $\mathrm{N}$ & ZE & $\mathrm{P}$ \\
\cline { 2 - 7 } & $\mathbf{Z E}$ & $\mathrm{N}$ & $\mathrm{N}$ & $\mathrm{ZE}$ & $\mathrm{P}$ & $\mathrm{P}$ \\
\cline { 2 - 7 } & $\mathbf{P}$ & $\mathrm{N}$ & $\mathrm{ZE}$ & $\mathrm{P}$ & $\mathrm{PL}$ & $\mathrm{PL}$ \\
\cline { 2 - 7 } & $\mathbf{P L}$ & $\mathrm{ZE}$ & $\mathrm{P}$ & $\mathrm{PL}$ & $\mathrm{PL}$ & $\mathrm{PL}$ \\
\hline
\end{tabular}

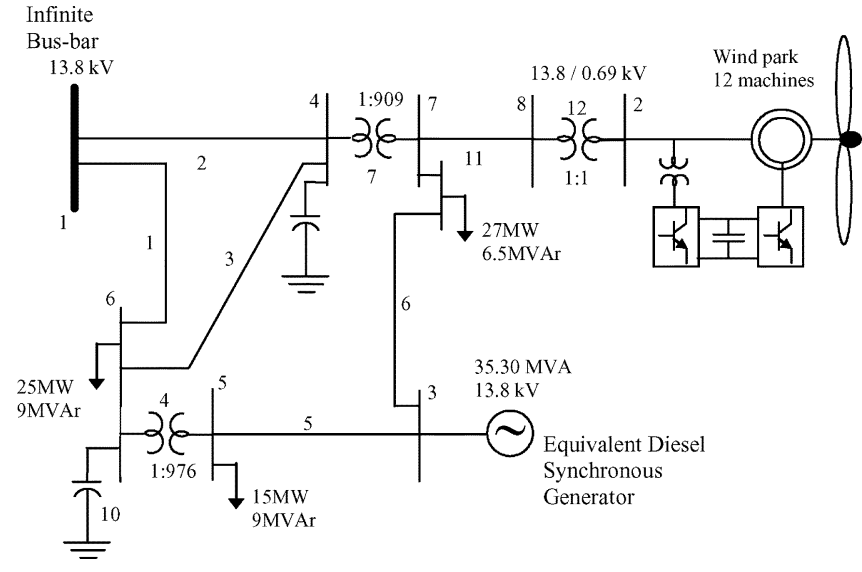

Fig. 7. Single-line diagram of the used test system.

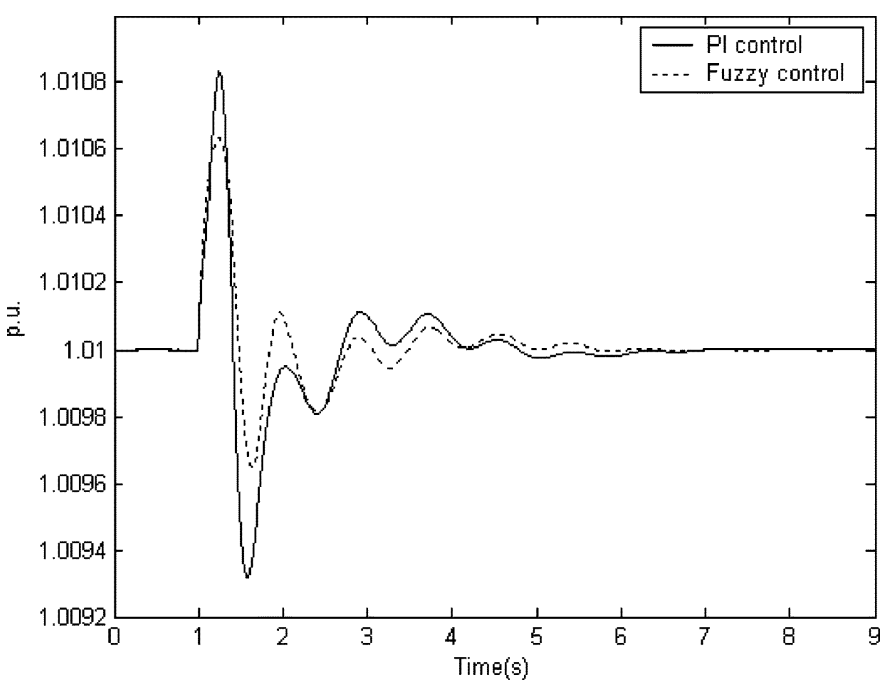

Fig. 8. Rotor speed behavior with PI and fuzzy controllers for loss load in bus-bar 5 .

rotor flux and, consequently, the rotor current. In other words, the DFIM consumes more reactive power after the load loss. Nonetheless, the converter $\mathrm{C} 2$ can be used to compensate the reactive power consumed by DFIM through a defined control strategy to improve the power factor of the system. The rotor current behavior is depicted in Fig. 10.

\section{B. Symmetrical Impedance Three Phase Short Circuit}

The objective of this simulation is to study the performances of both (PI and fuzzy) controllers regarding the dynamic stability of the power system when it is submitted to a more se-

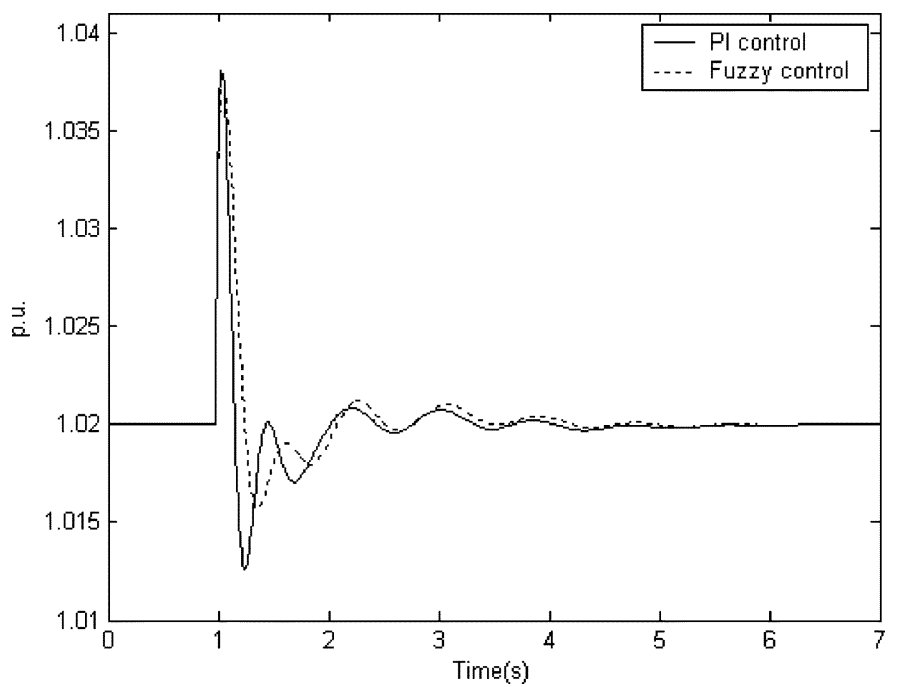

Fig. 9. Terminal voltage behavior with PI and fuzzy controllers for load loss in bus-bar 5 .

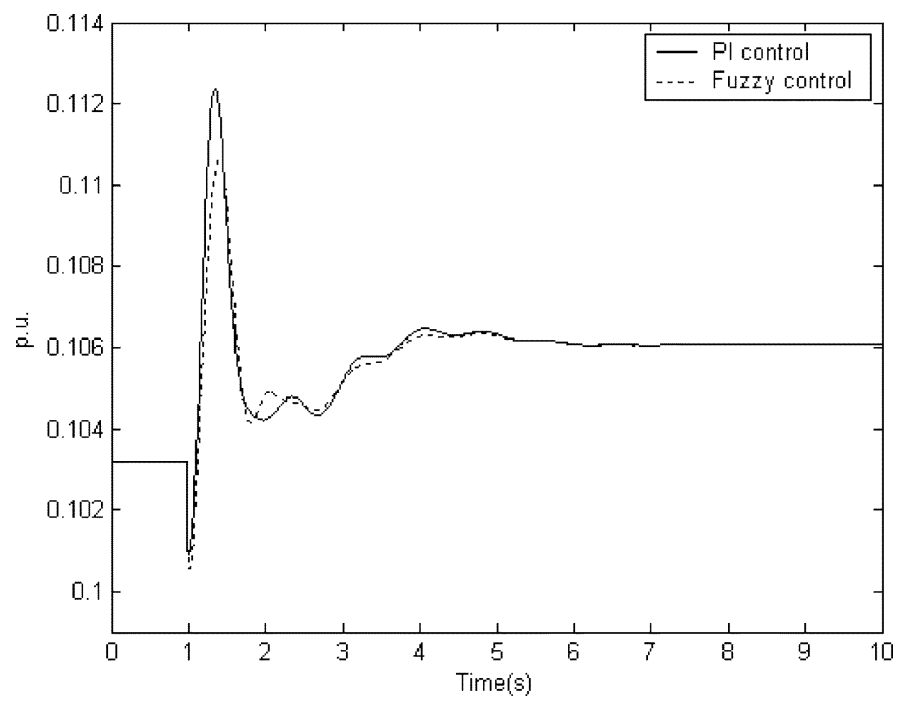

Fig. 10. Rotor current behavior for load loss at bus-bar 5 .

vere fault. This includes an evaluation of the rotor current behavior that could trigger-on the crowbar circuit when the protection limit is exceeded, reducing in this way the controlling capability of the DFIM during the short circuit. The crowbar is supposed to be triggered on if rotor current $i_{r}>0.18$ p.u., on the induction machine base (this is equivalent to $i_{r}>1.25 \mathrm{kA}$ for each machine). On the other hand, it is assumed that the machine would have to be disconnected from the grid by protective relays for voltages at the connecting bus outside the range of $1.15<V_{t}<0.7 \mathrm{p} . u$. The voltage and current limits are defined depending on the capacity of the generator and the rating of the converters. For this study, both limits were defined from fixed operation conditions considering operational aspects of the machine and converters, respectively.

It is assumed a typical clearing time (duration of the short-circuit) equal to $100 \mathrm{~ms}$. The clearing time is very important for the stability and the security of the system [7], [8]. During the fault, if the rotor current exceeds the current limit, the rotor 


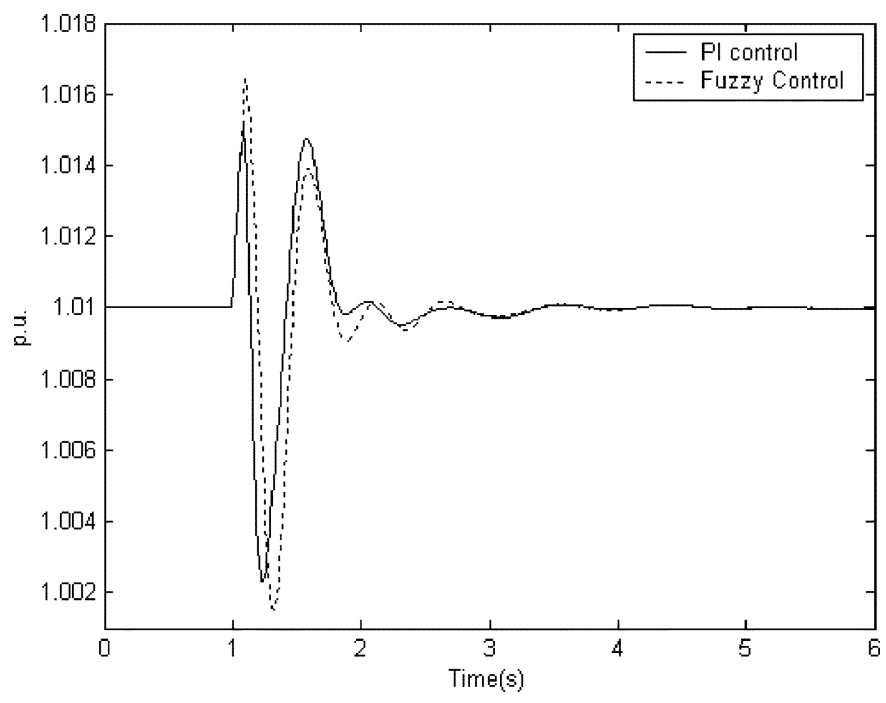

Fig. 11. Rotor speed with PI and Fuzzy controllers during symmetrical impedance fault at bus-bar 6 .

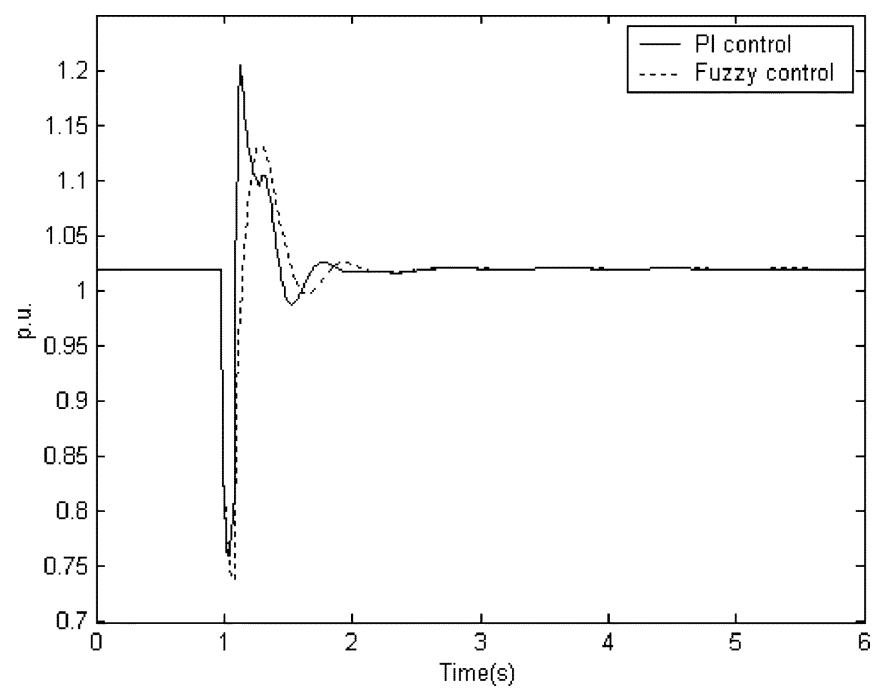

Fig. 12. Terminal Voltage behavior with PI and Fuzzy controllers during symmetrical impedance fault at bus-bar 6 .

is short-circuited through the crowbar and after fault elimination the $\mathrm{AC} / \mathrm{DC} / \mathrm{AC}$ link is again reconnected to the rotor after $150 \mathrm{~ms}$ with the crowbar triggered-off before.

Results: For illustration purposes, a symmetrical impedance short circuit is applied on the system at $\mathrm{t}=1 \mathrm{~s}$ at bus-bar 6 . Figs. 11-14 depict the rotor speed, terminal voltage, rotor current and electrical torque behaviors following the short circuit. In this case, it was observed that the fuzzy control would be able to keep the machine connected to the grid while with PI control this fact would not be possible because the upper voltage limit would be exceeded. On the other hand, when the PI is controlling the DFIM, the crowbar is triggered-on and the operation points of the machine are changed during a short period of time. However, if the protection regulation settings were more strict and the controls were not be able to damp the current oscillations, the crowbar could be trigged several times due to the current overshoot following the connection of the converters. In this case, the machine performance would be significantly poor. The

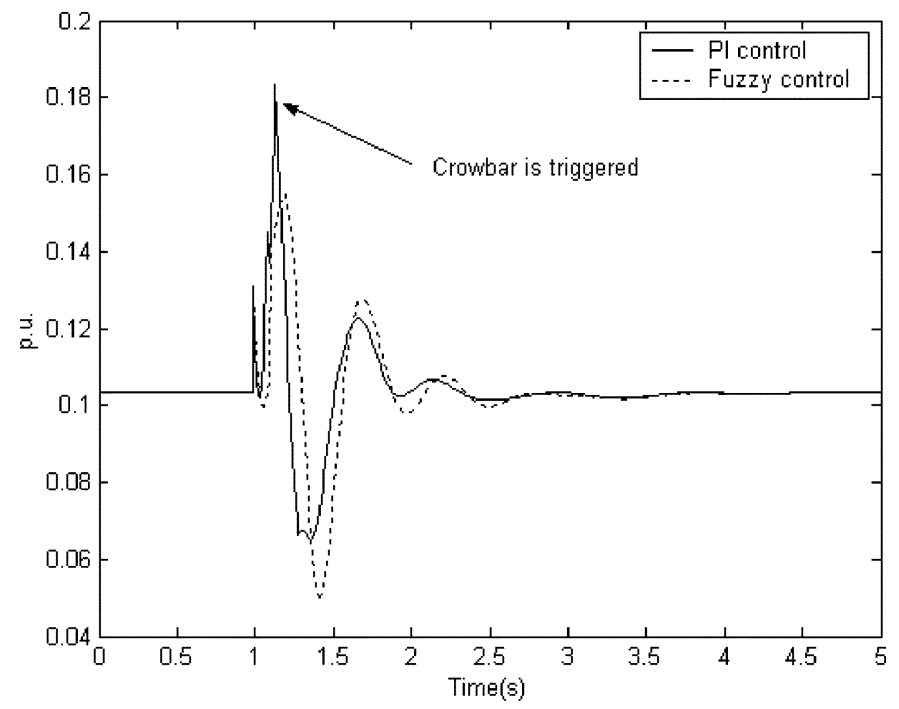

Fig. 13. Rotor current behavior with PI and Fuzzy controllers during symmetrical impedance fault at bus-bar 6 .

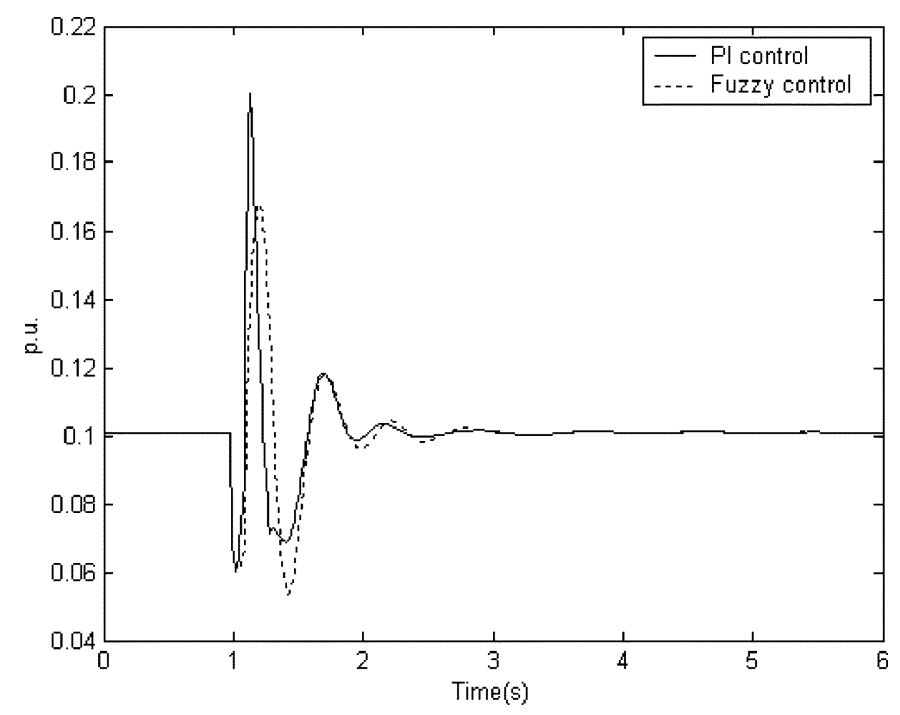

Fig. 14. Electrical torque behavior of the DFIM with PI and fuzzy controllers during symmetrical impedance fault at bus-bar 6 .

nonlinear and coupling terms cause a poor performance for the PI controllers and a new tuning of the gains would be necessary.

In Fig. 14, it can be observed the electrical torque behavior using both control approaches. Larger first oscillation can be observed in the machine with PI control as a result of the crowbar operation. During the short circuit, the fuzzy controllers perform more robustly, in spite of the fact that the membership functions and the rules were not carefully adjusted as in the PI controller design.

It is well known that the type of fuzzy implementation adopted in this work (a design made to replace PI controllers) presents better performance than a conventional PI counterpart when the control inputs are large (great excursion in relation to the reference values) and similar performance when they are small. It is due to the nonlinear action inherent in fuzzy control [20]. Therefore, although no optimization methods were used for both controllers, fuzzy controllers can have a better whole 
performance in systems that are subject to great perturbations as in power system applications.

\section{CONCLUSIONS}

The integration of DFIM and their control approach in a dynamic simulation software tool is required to evaluate the dynamic stability behavior of power systems with a large integration of these wind type systems. Using several tests, it was shown that, although PI controllers could play an important role in stability of the DFIM, they must be carefully designed. The alternative of using fuzzy controller may represent a robust tool to control these machines due to nonlinear and coupling presence in DFIM equations. It is also possible to adopt PI controllers as shown in this work, but a large amount of simulations is need to meet the acceptable range of gains while the fuzzy controllers were adjusted in just a few simulations. The effectiveness of the proposed scheme was evaluated through digital simulations and it was shown that it could be used to improve the dynamic behavior of power systems containing wind parks with DFIM.

Taking into account the increasing use of wind generators in power systems, such a control approach on these generators can provide an effective impact on the robustness of operation, following systems disturbances (specially short-circuits in the grid), reducing the possibilities of having their disconnection from the grid, and contributing also afterwards to keep the system dynamically stable.

\section{APPENDIX}

\section{A. Parameters}

Base values for the per-unit system conversion.

Base Power: 100 MVA

Base Voltages: $0.69 \mathrm{kV}$ for low-voltage bus-bar and $13.8 \mathrm{kV}$ for medium-voltage bus-bar.

\section{B. Equivalent Diesel Synchronous Generator}

$$
S_{n}(\mathrm{MVA})=35, V_{n}(\mathrm{kV})=13.8, R_{s}(\mathrm{pu})=0.0014,
$$
$X_{d}(\mathrm{pu})=14, X_{q}(\mathrm{pu})=1.372, X_{d}^{\prime}=0.231, X_{d}^{\prime \prime}(\mathrm{pu})=$ $0.118, X_{q}^{\prime}(\mathrm{pu})=0.800, X_{q}^{\prime \prime}(\mathrm{pu})=0.118, T_{d o}^{\prime}(\mathrm{s})=5.5$, $T_{d o}^{\prime \prime}(\mathrm{s})=0.050, T_{q o}^{\prime \prime}(\mathrm{s})=0.190$

\section{Equivalent Diesel Engine}

$$
T_{D}=0.1, H_{D}=4.390
$$

\section{Doubly Fed Induction Machine and the Link AC-DC-AC}

$P_{n}(\mathrm{~kW})=660, V_{n}(\mathrm{kV})=0.69, R_{s}(\mathrm{pu})=0.0067$, $X_{s}(\mathrm{pu})=0.03, R_{r}(\mathrm{pu})=0.0058, X_{r}(\mathrm{pu})=0.0506$, $X_{m}(\mathrm{pu})=2.3161, \omega_{s}=1500 \mathrm{rpm}$, No. of poles $=4$, rated slip generator $=2 \%$, DC Voltage $=258.75 \mathrm{~V}$,

Capacitor $=13.62 \mu \mathrm{F}$

Rotor transformer reactance : $9.5 \%$

$$
\frac{\text { Recovery-transformer primary }}{\text { secondary voltage ratio }}=1: 0.4348 \text {. }
$$

\section{E. Parameters of Wind Turbine}

No. of blades $=3$, rotor diameter $=22 \mathrm{~m}$, cut-in speed $=$ $4 \mathrm{~m} / \mathrm{s}$, cut-off speed $=25 \mathrm{~m} / \mathrm{s}$, Atm. Density $=1.225 \mathrm{Kg}$. $\mathrm{m}^{-3}$, Inertia time constant $=6.3$, gear box $=55$.

\section{ACKNOWLEDGMENT}

One of the authors, J. A. L. Barreiros would like to acknowledge UFPA (The Federal University of Pará-BR) and CAPES (an organ of the Brazilian Ministry of Education and Culture) for the support during his sabbatical leave term at INESC-Porto-PT, where this work was carried out.

\section{REFERENCES}

[1] N. Hatziargyriou et al., "CIGRE technical brochure on modeling new forms of generation and storage," CIGRE, TF 38.01.10, 2000.

[2] A. Feijoo et al., "A third order model for the doubly-fed induction machine," Elect. Power Syst.. Res., vol. 56, pp. 121-127, 2000.

[3] M. Machmoum et al., "Dynamic performance of a doubly-fed inductions machine for a variable-speed wind energy generation," in Proc. PowerCon2002, vol. 4, Oct. 2002, pp. 13-17.

[4] M. A. Pöller, "Doubly-fed induction machine models for stability assessment of wind farms," in Proc. IEEE Power Tech Conf., Bologna, Italy, June 2003.

[5] J. B. Ekanayake et al., "Dynamic modeling of doubly fed induction generator wind turbines," IEEE Trans. Power Syst., vol. 18, pp. 803-809, May 2003.

[6] J. G. Slootweg, "Wind Power: Modeling and Impact on Power System Dynamic," Ph.D. dissertation, Tech. Univ. Delft, Delft, The Netherlands, 2003.

[7] G. S. Stavrakakis and G. N. Kariniotakis, "A general simulation algorithm for the accurate assessment of isolad diesel - Wind turbines systems interaction - Part II: Implementation of algorithm and case-studies with induction generators," IEEE Trans. Energy Conversion, vol. 10, pp. 584-590, Sept. 1995.

[8] M. V. A. Nunes, U. H. Bezerra, and H. H. Zürn, "Transient stability margin of variable versus fixed speed wind systems in electrical grids," in Proc. IEEE Power Tech. Conf., Bologna, Italy, June 2003.

[9] J. M. Rodriguez et al., "Incidence on power system dynamics of high penetration of fixed speed and doubly fed wind energy systems: Study of the Spanish case," IEEE Trans. Power Syst., vol. 17, pp. 1089-1095, Nov. 2002.

[10] C. C. Lee, "Fuzzy logic in control systems: Fuzzy logic controller," IEEE Trans. Syst., Man, Cybern., vol. 20, pp. 404-418, Mar./Apr. 1990.

[11] M. A. M. Prats et al., "Improving transition between power optimization and limitation of variable speed, variable pitch wind turbines using fuzzy control," in Proc. IEEE Industrial Electronics Society Conf., vol. 3, Oct. 2000, pp. 1497-1502.

[12] H. Akagi et al., "Instantaneous reactive power compensators comprising switching devices without energy storage components," IEEE Trans. Ind. Applicat., vol. IA-20, pp. 625-630, May/June 1984.

[13] S. K. Salman and A. L. J. Leo, "Windmill modeling considerations and factor influencing the stability of grid-connected wind power-based embedded generator," IEEE Trans. Power Syst., vol. 18, May 2003.

[14] J. G. Slootweg et al., "Dynamic modeling of a wind turbine with doubly fed induction generator," in Proc. IEEE Power Eng. Soc. Summer Meeting, Vancouver, BC, Canadá, July 2001.

[15] K. J. Åstrom and T. Hägglund, PID Controllers: Theory, Design, and Tuning. Research Triangle Park, NC: Instrument Society of America, 1995.

[16] P. M. Anderson, Analysis of Faulted Power System. Ames, IA: The Iowa State University Press, 1973.

[17] G. S. Stavrakakis and G. N. Kariniotakis, "A general simulation algorithm for the accurate assessment of isolad diesel - Wind turbines systems interaction - Part I: A general multimachine power system model,' IEEE Trans. Energy Conversion, vol. 10, pp. 577-583, Sept. 1995.

[18] P. Kundur, Power System Stability and Control. New York: McGrawHill, 1994.

[19] J. Machowski et al., Power System Dynamics and Stability. New York: Wiley, 1997.

[20] H. Li et al., Fuzzy Neural Intelligent System. Boca Raton, FL: CRC, 2001. 


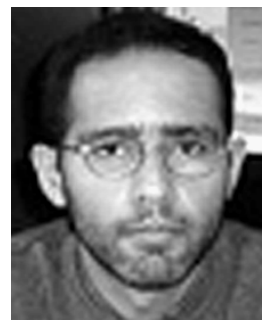

Rogério G. de Almeida received the B.Sc. degree in 1996 and the M.Sc. degree in 1999, both from the from Federal University of Pará, Pará, Brazil. $\mathrm{He}$ is currently working toward the Ph.D. degree at the Power System Unit of INESC, Porto, Portugal, studying the effects of large technology on power system dynamics, namely, renewable energy generation.

His main interests are focused on power system dynamic analysis, electrical machines, and power electronics.

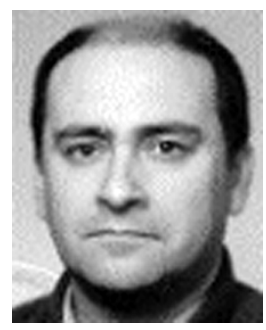

J. A. Peças Lopes (M'80-SM'94) received the electrical engineering degree and the Ph.D. degree, both in electrical engineering, from the University of Porto, Porto, Portugal, in 1981 and 1988, respectively. In 1996, he received the Aggregation degree.

$\mathrm{He}$ is an Associate Professor with the Department of Electrical Engineering, University of Porto. In 1989, he joined INESC, Porto, as a Senior Researcher and he is presently Co-Coordinator of the Power Systems Unit of INESC Porto.

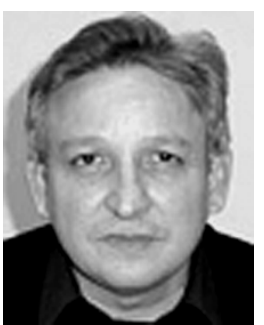

J. A. L. Barreiros received the M.Sc. degree in electrical engineering from The University of Manchester Institute of Science and Technology, Manchester, U.K., in 1989, and the Ph.D. degree in electrical engineering from Federal University of Santa Catarina, Santa Catarina, Brazil, in 1995.

He has been with Federal University of Pará, Pará, Brazil, since 1976, where he is presently a Titular Professor. His main areas of research are control systems and applications of control in power systems. 